\title{
LIFE SATISFACTION, DENTAL EXPERIENCES AND AUTO PERCEPTION OF ORAL HEALTH AMONG PATIENTS WITH AUTOIMMUNE DISEASE.
}

Ana Teresa Amoedo (UEFS, Feira de Santana, BA, Brasil), Hilda Mendes Nery Neta (UEFS, Feira de Santana, BA, Brasil), Deyse Conceição Sales (UEFS, Feira de Santana, BA, Brasil), Wanessa Maria de

Freitas Aras (UEFS, Feira de Santana, BA, Brasil), Tarsila Carvalho Freitas Ramos (UEFS, Feira de Santana, BA, Brasil), Silvania Cápua Carvalho (UEFS, Feira de Santana, BA, Brasil)

\section{BACKGROUND}

Quality of life is related to the self perception of the human being in his daily life.

\section{MATERIALS AND METHODS}

Cross-sectional / descriptive study of data obtained through a questionnaire applied to patients attended at a rheumatologic center. The research under resolution 466/12 was approved by the Ethics Committee on Research on Human Beings (CAAE: 0015.0.059.000-08).

\section{RESULTS}

The epidemiological profile: female (80\%), faioderma (31.4\%) and 45 years as mean age. Prevalent rheumatologic diseases: systemic lupus erythematosus (42.86\%) and rheumatoid arthritis (31.43\%). Main oral complaints: dry and / or bitter mouth (28.57\%); lack of teeth (37.14\%); gingiva bleeds (22.85). Regarding dental treatment, $65.71 \%$ confirmed the need and $42.85 \%$ used a prosthesis, $60 \%$ of which required replacement. Only $2.85 \%$ of the individuals considered oral health to be optimal.

\section{CONCLUSION}

It is concluded that specialized dental care and the use of palliatives to relieve discomfort / pain should be performed by multiprofessional teams directed to patients with autoimmune disease. 